\title{
Validation of the Spiritual Distress Scale in Portuguese Cancer Patients Undergoing Chemotherapy: A Methodological Study
}

\author{
Helga Martins ${ }^{1}{ }^{\mathbb{D}}$, Sílvia Caldeira ${ }^{1, *}$, Tiago Dias Domingues ${ }^{2}$, Margarida Vieira ${ }^{3}$ and Ya-Lie Ku ${ }^{4}$ \\ 1 Centre for Interdisciplinary Research in Health, Institute of Health Sciences, \\ Universidade Católica Portuguesa, Palma de Cima, 1649-023 Lisbon, Portugal; helga.t.martins@gmail.com \\ 2 Centre of Statistics and Its Applications, Universidade de Lisboa, 1649-004 Lisbon, Portugal; \\ tmdomingues@fc.ul.pt \\ 3 Centre for Interdisciplinary Research in Health, Institute of Health Sciences, \\ Universidade Católica Portuguesa, Rua de Diogo Botelho 1327, 4169-005 Oporto, Portugal; \\ mmvieira@porto.ucp.pt \\ 4 College of Nursing, Fooyin University, Kaohsiung City 83102, Taiwan; ns126@fy.edu.tw \\ * Correspondence: scaldeira@ics.lisboa.ucp.pt
}

Received: 23 June 2019; Accepted: 16 October 2019; Published: 28 October 2019

\begin{abstract}
Spiritual distress may ascend from unmet spiritual needs. The use of instruments to measure spiritual distress seems to facilitate the approach to spirituality, such as the Spiritual Distress Scale (SDS) that has been used worldwide. No instrument to assess spiritual distress in cancer patients is currently available in Portugal. This study aims to conduct the translation, adaptation and validation of the SDS in Portuguese cancer patients undergoing chemotherapy. Methodological study based on Sousa and Rojjanasrirat (2011), a seven-step approach, started with the linguistic translation to the psychometric tests. The main participants (55.4\%) were older than 60 years; about $64.7 \%$ were females, married $(68.0 \%)$, and $86.7 \%$ were Catholic. Moderate spiritual distress was experienced by $49.3 \%$ of the participants. Linguistic and conceptual equivalences were obtained. The SDS European Portuguese version has an overall Cronbach's alpha of 0.91, and the subscales were as follows: "relationship with self" (0.92), "relationship with others" (0.63), "relationship with God" (0.64) and "facing death" (0.85). Four factors emerged after Varimax rotation. Overall, these results indicate that the SDS European Portuguese version has good psychometric characteristics and can used in assessing spiritual distress in cancer patients.
\end{abstract}

Keywords: assessment; cancer; nursing; spiritual distress; tool; validation

\section{Introduction}

Spiritual distress is a deep and intimate experience, shrouded in great suffering from the patients (Martins and Caldeira 2018). Spiritual distress arises when an individual experiences suffering that challenges the sense of purpose and personal identity (Caldeira et al. 2017). According to Caldeira et al. (2013) the prevalence of spiritual distress is $40.8 \%$ in cancer patients undergoing chemotherapy. Also, high scores of depression have been associated with spiritual distress (Kopacz et al. 2015; Velosa et al. 2017) and risk for suicide (Kopacz et al. 2015).

Nurses often describe difficulty in addressing spiritual distress mainly because of perceiving a lack of education or experience, as well as failure to listen deeply and respond empathically to patients' spiritual needs (Taylor and Mamier 2013).

Spiritual distress (00066) is a nursing diagnosis listed in NANDA International, Inc. (NANDA-I) since 1978 (Herdman and Kamitsuru [1994] 2018). Lately, Caldeira et al. (2013, p. 6) performed a 
concept update of spiritual distress and defined this as "a state of suffering related to the impaired ability to experience meaning in life through connectedness with self, others, world or a Superior Being" (Caldeira et al. 2013, p. 82). More recently, Martins and Caldeira (2018) conducted a synthesis of qualitative studies of spiritual distress, and the major theme of "suffering" emerged as foundational, which was triggered by alienation, anger, anxiety, body image, burden to family, crying, disconnected, fatalism, fear, forgiveness, good death/desire to die, guilt/punishment, hopelessness, impaired role performance, insomnia, lack of autonomy/dignity, lack of relative and friends support, loneliness, loss of self/lost identity, physical symptoms, refusing to see relatives, relationship with God, social isolation, uncertain future and worthlessness.

Assessing the diagnosing spiritual distress can be a difficult and complex task (Martins et al. 2015). As claimed by Bornet et al. (2016), spiritual distress ascends from unmet spiritual needs. Therefore, assessing the spiritual needs of patients is fundamental for nursing practice (Caldeira et al. 2019; Draper 2012). Lately, Büssing et al. (2018) performed the factor structure of the Spiritual Needs Questionnaire in persons with chronic diseases, elderly and healthy individuals. This scale in an added value to clinical practice since it was found to be reliable in different participants, facilitating an objective assessment of spiritual needs. In fact, there has been an effort towards developing new instruments to assess the spiritual needs of patients (Monod et al. 2011). In order to get a better understanding of the different tools available to assess spiritual distress, the latest reviews concerning this topic are presented. Seddigh et al. (2016) conducted a review and identified eight questionnaires which allowed the assessment of spiritual needs of patients. Best et al. (2015) completed a systematic literature review and only found the Spiritual Distress Scale (Ku et al. 2010) that measured the spiritual distress construct. More recently, Bahraini et al. (2019) performed a systematic review regarding the accuracy of measures in screening adults for spiritual suffering and identified 24 spiritual screening measures, although few had sufficient accuracy to assess spiritual suffering in health care settings. However, the Spiritual Dryness Scale is a valid instrument that assesses if individuals experienced a spiritual crisis (Büssing et al. 2013).

Currently, worldwide, there is little variety of scales that allow an accurate assessment of the spiritual distress diagnosis in clinical practice. At this moment, there is no validated instrument to assess spiritual distress in Portuguese cancer patients, but only scales that measure spiritual well-being. Thus, conducting the validation of an instrument to assess spiritual distress, particularly in cancer patients, seems essential, as nurses and healthcare providers will have available a tool to support the assessment, diagnosis and intervention.

This study aims to conduct the translation, adaptation and validation of the psychometric properties of the Portuguese European version of the Spiritual Distress Scale (SDS) in cancer patients.

\section{Methods}

\subsection{Design}

This is a methodological study, and the process of translation, adaptation and validation of the cultural characteristics of a population requires the planning of a set of steps to attain a reliable and valid measure (Sousa and Rojjanasrirat 2011).

The methodological approach used was the guideline by Sousa and Rojjanasrirat (2011), that is a seven-step approach these authors developed for translation, adaptation and validation of instruments or scales for use in cross-cultural health care research.

Step 1: translation of the original instrument into the target language

The original instrument (English) was translated to the target language (Portuguese) by two independent translators (TL1 and TL2) who were bilingual and certified translators, whose native language was Portuguese. One of the translators had experience and knowledge in health terminology and the construct of the instrument that was validated. 
Step 2: comparison of the two translated versions of the instrument (TL1 and TL2): synthesis I

The two translated versions TL1 and TL2 were compared. To achieve synthesis I, a third independent bilingual translator was added. Finally, to achieve the preliminary instrument, a consensus between the three translators and the two main researchers was performed.

Step 3: blind back-translation (blind backward translation or blind double translation) of the preliminary initial translated version of the instrument

The next step was to translate the preliminary instrument back into English. A blind double translation required two bilingual certificated translators, whose native language is English. The required characteristics of the translators are similar to step 1 (one of the translators had to have experience and knowledge of health terminology and the constructs of the instrument that was validated).

Step 4: comparison of the two back-translated versions of the instrument (B-TL1 and B-TL2): synthesis II

In this step, a multidisciplinary committee was used in order to obtain the conceptual equivalence of the items of the instrument process. Ambiguities or discrepancies were found. However, after discussion, consensus was reached, and synthesis II was obtained.

Step 5: pilot testing of the pre-final version of the instrument in the target language with a monolingual sample: cognitive debriefing

A pilot test of the pre-final version was conducted in 20 cancer patients undergoing chemotherapy. Each participant was asked to evaluate the items of the scale with a dichotomy answer "clear" or "not clear". The inter-rater agreement in the pilot test was $98.10 \%$, which was a positive outcome), as a minimum of $80.0 \%$ inter-rater agreement of the sample is needed to ensure conceptual, semantic and content equivalency (Sousa and Rojjanasrirat 2011). The next stage to determine conceptual and the content equivalence of the construct of the instrument was the use of an expert panel. Sousa and Rojjanasrirat (2011) recommend a minimum of six to ten experts. Nine expert committees were used in this study in order to evaluate each item of the instrument intended for content equivalence. The results of the panel of experts showed that the content validity index at the item level and at the scale level was above 0.90 , as recommended.

Step 6: preliminary psychometric testing of the pre-final version of the translated instrument with a bilingual sample

This step was not performed because it is not mandatory in the authors' guideline, since it is difficult to achieve a bilingual sample.

Step 7: full psychometric testing of the pre-final version of the translated instrument in a sample of the target population

The final step of the full psychometric testing is explained in detail in the following subthemes.

\subsection{Setting}

Participants were recruited at the Oncology Day Unit of a hospital in the south of Portugal. 


\subsection{Population and Sampling}

A convenience sampling procedure was used to recruit participants. The sample size was achieved according to the rule that each item on the scale required five questionnaires (Munro [1986] 2005). Since the SDS has 30 items, the estimated sample size was 150 participants. Sousa and Rojjanasrirat (2011) recommend a sample size between 300-500 participants, but this was not possible to fulfill, based on time, resources and number of patients with the criteria to be enrolled.

The inclusion criteria of this study included the following: cancer patients who attended the Oncology Day Unit of a hospital and were able to give written consent, patients undergoing chemotherapy (intravenous, oral and subcutaneous), 18 years and over, and being able to read and write.

The sample consisted of 150 participants, 53 males (35.3\%) and 97 females (64.7\%). Ages ranged from 35 to 83 years old $(M=59.50 ; \mathrm{s}=11.24)$. More demographic characteristics are summarized in Table 1.

\subsection{Instrument}

The SDS is a valid tool to assess spiritual distress of cancer patients (Ku et al. 2010). The SDS started in 2003 and 2004, by Ku (2005), who developed a qualitative scale in order to assess spiritual distress in 20 cancer patients from chemotherapy clinics in southern Taiwan. In 2010, the validation of the Spiritual Distress Scale was originally conducted. In this step, Ya Lie-Ku required the collaboration of two other researchers. This quantitative scale was applied to 85 cancer patients who were admitted to the oncology service at a medical center in southern Taiwan. The scale is composed of 30 items and four domains: "relationship with self" (14 items), "relationship with others" (five items), "relationship with God" (seven items) and "facing death" (four items). As such, the subscales of the SDS concern different areas, specifically in the domain "relationship with self", patients emotion and thoughts are assessed; in the domain "relationship with others", the relationship with others is explored; "relationship with God" relates to the relationship with God and the religious practices of the individuals; and in the domain "facing death", the focus is on patients' inability to discuss death or whether they are afraid to die (Ku 2005). Each item is scored from 1-4, and the scores range between 30-120. A higher score indicates a higher level of spiritual distress. Additionally, the SDS has a global Cronbach's alpha of 0.95.

The Spiritual Well-Being Questionnaire (SWBQ) (Gomez and Fisher 2003; Gomez and Fisher 2005a, 2005b; Gouveia et al. 2009) was used to perform the divergent validity. The SWBQ is comprised of 20 items and is divided into four subscales: personal (items 5, 9, 14, 16, and 18), communal (items 1, 3, 8, 17, and 19), environmental (items 4, 7, 10, 12, and 20) and transcendental (items 2 , 6, 11, 13, and 15) (Gomez and Fisher 2003). The personal domain is related to the way people relate to themselves and with the meaning, purpose and values in life; the communal domain is associated with interpersonal relations regarding morality, culture and religion; the environmental domain embraces the physical and biological relationships; and the transcendental domain refers to relationship with a higher force (Gouveia et al. 2009). This instrument allows participants' reply using a five-point Likert scale, and the scores of the SWBQ range between 20 to 100. Furthermore, the SWBQ has a global Cronbach's alpha of 0.89 (Gouveia et al. 2009). In fact, as no other instrument concerning spiritual distress was available in Portugal, the SWBQ was used considering previous studies that found that cancer patients undergoing chemotherapy and having spiritual distress had lower scores of spiritual well-being (Caldeira et al. 2017). 
Table 1. The characteristics of the participants.

\begin{tabular}{|c|c|c|}
\hline Variable & $n$ & $\%$ \\
\hline \multicolumn{3}{|l|}{ Gender } \\
\hline Male & 53 & 35.3 \\
\hline Female & 97 & 64.7 \\
\hline \multicolumn{3}{|l|}{ Age group } \\
\hline $35-39$ & 8 & 5.3 \\
\hline $40-59$ & 59 & 39.3 \\
\hline $60-79$ & 82 & 54.7 \\
\hline $80-99$ & 1 & 0.7 \\
\hline \multicolumn{3}{|l|}{ Age range (35-83 years) } \\
\hline \multicolumn{3}{|l|}{$\mathrm{M}=59.50 \pm \mathrm{s}=11.24$} \\
\hline \multicolumn{3}{|l|}{ Marital status } \\
\hline Single & 11 & 7.3 \\
\hline Married & 102 & 68.0 \\
\hline Widower & 13 & 8.7 \\
\hline Divorced & 15 & 10.0 \\
\hline Unmarried & 9 & 6.0 \\
\hline \multicolumn{3}{|l|}{ Educational level } \\
\hline $1^{\circ}$ Cycle & 53 & 35.3 \\
\hline $2^{\circ}$ Cycle & 11 & 7.3 \\
\hline $3^{\circ}$ Cycle & 25 & 16.7 \\
\hline High school & 38 & 25.3 \\
\hline Diploma/Degree & 22 & 14.7 \\
\hline Master's degree & 1 & 0.7 \\
\hline \multicolumn{3}{|l|}{ Professional occupation } \\
\hline Specialists in intellectual and scientific activities & 18 & 12.0 \\
\hline Middle level technicians and professions & 6 & 4.0 \\
\hline Administrative staff & 4 & 2.7 \\
\hline Workers in personal and protective services & 1 & .7 \\
\hline Farmers and skilled workers & 7 & 4.7 \\
\hline Skilled industry workers & 7 & 4.7 \\
\hline Plant and machine operators & 2 & 1.3 \\
\hline Unskilled workers & 34 & 22.7 \\
\hline Retired & 62 & 41.3 \\
\hline Domestic & 7 & 4.7 \\
\hline Unemployed & 2 & 1.3 \\
\hline \multicolumn{3}{|l|}{ Religion } \\
\hline Catholic & 130 & 86.7 \\
\hline Protestant & 9 & 6.0 \\
\hline Agnostic & 11 & 7.3 \\
\hline \multicolumn{3}{|l|}{ Clinical diagnosis } \\
\hline Lung & 23 & 15.3 \\
\hline Pancreas & 2 & 1.3 \\
\hline Colorectal & 39 & 26.0 \\
\hline Uterus & 6 & 4.0 \\
\hline Breast & 53 & 35.3 \\
\hline Stomach & 3 & 2.0 \\
\hline Prostate & 6 & 4.0 \\
\hline Others & 6 & 4.0 \\
\hline Non-Hodgkin's lymphoma & 5 & 3.3 \\
\hline Hodgkin's lymphoma & 2 & 1.3 \\
\hline Multiple myeloma & 3 & 2.0 \\
\hline Testicles & 1 & 0.7 \\
\hline Liver & 1 & 0.7 \\
\hline
\end{tabular}




\subsection{Data Collection}

Data collection was conducted from 14 July to 4 October 2018. Participants were recruited from the Oncology Day Unit of a hospital, and the first approach was to invite the participants. After informed consent was obtained, a self-completion questionnaire was given to each participant. This questionnaire included demographics, clinical condition and the SDS scale. Participants were informed that it may take $15 \mathrm{~min}$ to complete, and in case of any doubts regarding the questionnaire, a researcher was available to give full support and clarification.

The data collection was conducted by one researcher who had previous experience in collecting data. All data were entered into a Statistical Package for the Social Sciences (SPSS) sheet, double checked for bias in transcription and protected and accessed only by researchers.

\subsection{Data Analysis}

All statistical analyses were performed using SPSS software, version 21.0 (SPSS Inc., Chicago, IL, USA). In addition, descriptive statistics, correlations, reliability, exploratory factor analysis, divergent validity and Receiver Operating Characteristic (ROC) were performed. The concurrent validity was not performed as no other valid Portuguese tool was available. The $\alpha$ level of significance tests was 0.05 except noted otherwise.

\subsection{Ethical Considerations}

The recommended ethical procedures were followed. The author of the original scale was contacted, and the permission of the copyright was given.

Ethical approval was obtained from the Oncology Day Unit of a hospital in the south of Portugal. All participants provided written and verbal informed consent. Throughout the study, the confidentiality and anonymity of the participants were preserved. Also, they were reminded of their right to withdraw at any time of the study.

\section{Results}

\subsection{Descriptive Results of the SDS}

The overall M score of the SDS was $\mathrm{M}=61.57$ ( $\mathrm{s}=13.91$ ), and the scores ranged between 35-98. Descriptive results of the SDS of the SDS are summarized in Table 2.

Concerning the descriptive scores of the SDS scale, the item with the highest average score was item 24 "I feel sinful", and the item with the lowest M score was item 29, "I worry about my dying ceremony" (Table 3).

The data of the total the SDS results suggest that nearly half $(49.3 \%, n=74)$ of the participants experienced moderate spiritual distress, $44.0 \%(n=66)$ of participants had low spiritual distress, and a small portion of participants $(6.7 \%, n=10)$ had severe spiritual distress. The SDS had an area under the ROC curve (AUC) of 0.890 (95\% CI, 0.83-0.94) at an optimal cut-off value of 58.50 . 
Table 2. The characteristics and the total score of the SDS in the participants $(\mathrm{N}=150)$.

\begin{tabular}{|c|c|c|}
\hline Variable & Total Mean Score (M) & Standard Deviation (s) \\
\hline \multicolumn{3}{|l|}{ Gender } \\
\hline Male & 61.23 & 13.38 \\
\hline Female & 61.76 & 14.25 \\
\hline \multicolumn{3}{|l|}{ Age group } \\
\hline \multicolumn{3}{|l|}{$35-39$} \\
\hline $40-59$ & 60.13 & 5.32 \\
\hline $60-79$ & 64.15 & 1.93 \\
\hline $80-99$ & 59.98 & 1.43 \\
\hline \multicolumn{3}{|l|}{ Marital status } \\
\hline Single & 62.27 & 17.49 \\
\hline Married & 61.59 & 13.62 \\
\hline Widower & 59.00 & 10.25 \\
\hline Divorced & 62.47 & 19.01 \\
\hline Unmarried & 62.78 & 8.57 \\
\hline \multicolumn{3}{|l|}{ Educational level } \\
\hline $1^{\circ}$ Cycle & 59.77 & 13.79 \\
\hline $2^{\circ}$ Cycle & 68.82 & 11.99 \\
\hline $3^{\circ}$ Cycle & 64.80 & 14.49 \\
\hline High school & 60.87 & 12.45 \\
\hline Diploma/Degree & 58.86 & 15.52 \\
\hline Master's degree & 83.00 & \\
\hline \multicolumn{3}{|l|}{ Professional occupation } \\
\hline Specialists in intellectual and scientific activities & 60.33 & 15.69 \\
\hline Middle level technicians and professions & 65.50 & 10.89 \\
\hline Administrative staff & 70.25 & 19.75 \\
\hline Workers in personal and protective services & 75.00 & \\
\hline Farmers and skilled workers & 68.14 & 19.91 \\
\hline Skilled industry workers & 65.29 & 13.31 \\
\hline Plant and machine operators & 58.00 & 24.04 \\
\hline Unskilled workers & 61.35 & 14.30 \\
\hline Retired & 59.92 & 13.13 \\
\hline Domestic & 61.43 & 7.82 \\
\hline Unemployed & 60.00 & 2.82 \\
\hline \multicolumn{3}{|l|}{ Religion } \\
\hline Catholic & 61.91 & 14.07 \\
\hline Protestant & 55.56 & 13.36 \\
\hline Agnostic & 62.55 & 12.25 \\
\hline \multicolumn{3}{|l|}{ Clinical diagnosis } \\
\hline Lung & 62.62 & 12.47 \\
\hline Pancreas & 62.13 & 13.59 \\
\hline Colorectal & 56.74 & 14.53 \\
\hline Uterus & 50.50 & 12.02 \\
\hline Breast & 63.17 & 19.83 \\
\hline Stomach & 73.67 & 9.71 \\
\hline Prostate & 62.17 & 12.31 \\
\hline Others & 64.83 & 23.19 \\
\hline Non-Hodgkin's lymphoma & 64.40 & 11.86 \\
\hline Hodgkin's lymphoma & 60.00 & 25.45 \\
\hline Multiple myeloma & 58.33 & 16.07 \\
\hline Testicles & 50.00 & \\
\hline Liver & 59.00 & \\
\hline
\end{tabular}


Table 3. Items in English and European Portuguese and average scores on the SDS (N = 150).

\begin{tabular}{|c|c|c|c|c|}
\hline Item & SDS Items in English & SDS Items in European Portuguese & M (Range of Values: 1-5) & $\mathbf{s}$ \\
\hline & Domain: Relationship with self & Domínio: Relação com o próprio & 2.08 & 0.85 \\
\hline 1 & I feel shock & Sinto-me em choque & 1.90 & 0.86 \\
\hline 2 & I feel denial & Sinto-me em negação & 1.99 & 0.94 \\
\hline 3 & I feel fear & Sinto-me com medo & 2.41 & 0.77 \\
\hline 4 & I feel suffering & Sinto-me em sofrimento & 2.38 & 0.98 \\
\hline 5 & I feel sorrow & Sinto mágoa & 1.87 & 0.82 \\
\hline 6 & I feel loneliness & Sinto solidão & 1.99 & 0.87 \\
\hline 7 & I feel numb & Sinto entorpecimento (dormente) & 1.89 & 0.82 \\
\hline 8 & I feel regret & Sinto arrependimento & 1.95 & 0.80 \\
\hline 9 & I feel discontented & Sinto descontentamento & 2.21 & 0.89 \\
\hline 10 & I feel worry & Sinto preocupação & 2.70 & 0.88 \\
\hline 11 & I feel fatalism & Sinto fatalismo & 1.95 & 0.80 \\
\hline 12 & I feel like giving up the life & Sinto vontade de desistir da vida & 1.61 & 0.71 \\
\hline 13 & I feel pessimistic & Sinto-me pessimista & 2.21 & 0.86 \\
\hline \multirow[t]{2}{*}{14} & I feel something in my mind & Sinto algo na minha mente & 2.00 & 0.81 \\
\hline & Domain: relationship with others & Domínio: Relação com os outros & 2.15 & 0.80 \\
\hline 15 & I cannot be satisfied by others & Não consigo ser satisfeito por outros & 1.97 & 0.71 \\
\hline 16 & I cannot trust others & Não consigo confiar nos outros & 2.44 & 0.80 \\
\hline 17 & I cannot obey others & Não consigo obedecer aos outros & 2.27 & 0.71 \\
\hline 18 & I cannot forgive others & Não consigo perdoar os outros & 2.13 & 0.87 \\
\hline \multirow[t]{2}{*}{19} & I feel alienated from others & Sinto-me alienado (distante) dos outros & 1.96 & 0.89 \\
\hline & Domain: Relationship with God & Domínio: Relação com Deus & 2.03 & 0.95 \\
\hline 20 & I feel no respect for God & Não sinto respeito por Deus & 1.73 & 1.07 \\
\hline 21 & I feel God is powerless & Sinto que Deus é impotente & 2.13 & 1.12 \\
\hline 22 & $\begin{array}{l}\text { I feel no protection from my } \\
\text { ancestors }\end{array}$ & $\begin{array}{l}\text { Sinto que não sou protegido pelos meus } \\
\text { antepassados }\end{array}$ & 1.90 & 0.94 \\
\hline 23 & I feel tied up by my faith & Sinto-me preso pela minha fé & 1.61 & 0.75 \\
\hline 24 & I feel sinful & Sinto-me pecador & 2.43 & 0.74 \\
\hline 25 & I feel no peace of mind & Não sinto paz de espírito & 2.08 & 0.87 \\
\hline \multirow[t]{2}{*}{26} & I cannot attend religious activities & Não consigo participar em atividades religiosas & 2.35 & 1.14 \\
\hline & Domain: Facing death & Domínio: Encarar a morte & 1.89 & 0.87 \\
\hline 27 & I am afraid to discuss death & Tenho medo de conversar sobre a morte & 2.08 & 0.95 \\
\hline 28 & I worry about my dying situation & Preocupo-me com a situação da minha morte & 2.16 & 0.93 \\
\hline 29 & I worry about my dying ceremony & Preocupo-me com a minha cerimónia fúnebre & 1.58 & 0.75 \\
\hline 30 & $\begin{array}{l}\text { I worry about where I am going } \\
\text { after death }\end{array}$ & Preocupo-me para onde vou depois de morrer & 1.72 & 0.84 \\
\hline
\end{tabular}

The total M scores of the SDS were analyzed in detail: females, $(\mathrm{M}=61.76, n=97)$ and males, $(\mathrm{M}=61.23, n=53)$; the age group between 40 and 59 presented the highest total $\mathrm{M}$ score of the SDS $(\mathrm{M}=64.15, n=59)$. Concerning the religious affiliation, the highest $\mathrm{M}$ score of the SDS was obtained by Agnostic $(M=62.55, n=11)$, followed by Catholic $(M=61.91, n=10)$ and Protestant $(M=55.56, n=9)$. Analyzing the mean scores of various domains of the SDS, in the domain "relationship with self", the religious affiliation with the highest $M$ score was Catholic $(M=2.11)$, followed by Agnostic $M=1.95$ and Protestant $(M=1.78)$. Concerning the domain "relationship with self", the highest $\mathrm{M}$ score was Catholic $(M=2.11)$, Agnostic $(M=1.95)$ and Protestant $(M=1.78)$. In the domain "relationship with God", the religious affiliation with the highest $M$ score was Agnostic $(M=2.43)$, Catholic $(M=2.02)$ and Protestant $(M=1.79)$. Finally, in the domain "facing death", the religious affiliation with the highest $\mathrm{M}$ score was Catholic $(\mathrm{M}=1.90)$, followed by Agnostic $(\mathrm{M}=1.80)$ and Protestant $(\mathrm{M}=1.72)$.

\subsection{Exploratory Factor Analysis}

Kaiser-Meyer-Olkin (KMO) sampling adequacy showed a high score of 0.88 , and the Bartlett's Test of Sphericity was significant $(\chi 2=2316.94 ; \mathrm{df}=435 ; p=0.00)$, indicating that performing a factor analysis was appropriate.

Regarding the Principal Component Analysis (PCA), all 30 items had factor loadings values above 0.30. As a result, no item from the final scale was deleted, in agreement with Waltz et al. (Waltz et al. [1991] 2016), who recommends that the extraction values should be above 0.30 . The items with the highest extraction values were 19, 29 and 30; in addition, the lowest was item 23 (Table 4). 
Table 4. Principal component analysis of the SDS.

\begin{tabular}{lcc}
\hline \multicolumn{1}{c}{ Variable } & Initial & Extraction \\
\hline SDS 1 (shock) & 1.00 & 0.74 \\
SDS 2 (denial) & 1.00 & 0.55 \\
SDS 3 (fear) & 1.00 & 0.61 \\
SDS 4 (suffering) & 1.00 & 0.67 \\
SDS 5 (sorrow) & 1.00 & 0.49 \\
SDS 6 (loneliness) & 1.00 & 0.71 \\
SDS 7 (numb) & 1.00 & 0.73 \\
SDS 8 (regret) & 1.00 & 0.51 \\
SDS 9 (discontented) & 1.00 & 0.62 \\
SDS 10 (worry) & 1.00 & 0.58 \\
SDS 11 (fatalism) & 1.00 & 0.72 \\
SDS 12 (giving up) & 1.00 & 0.56 \\
SDS 13 (pessimistic) & 1.00 & 0.60 \\
SDS 14 (my mind) & 1.00 & 0.50 \\
SDS 15 (satisfied by others) & 1.00 & 0.51 \\
SDS 16 (trust others) & 1.00 & 0.51 \\
SDS 17 (obey others) & 1.00 & 0.58 \\
SDS 18 (forgive others) & 1.00 & 0.62 \\
SDS 19 (alienated) & 1.00 & 0.75 \\
SDS 20 (respect for God) & 1.00 & 0.73 \\
SDS 21 (God is powerless) & 1.00 & 0.59 \\
SDS 22(my ancestors) & 1.00 & 0.52 \\
SDS 23 (faith) & 1.00 & 0.40 \\
SDS 24 (sinful) & 1.00 & 0.54 \\
SDS 25 (peace of mind) & 1.00 & 0.60 \\
SDS 26 (religious activities) & 1.00 & 0.60 \\
SDS 27 (discuss death) & 1.00 & 0.71 \\
SDS 28 (dying situation) & 1.00 & 0.75 \\
SDS 29 (dying ceremony) & 1.00 & 0.75 \\
SDS 30 (after death) & 1.00 & \\
\hline & & \\
& &
\end{tabular}

According to the Guttman-Kaiser rule, the eigenvalue should be higher than one (Guttman 1954; Kaiser 1961). Therefore, the principal factor analysis revealed a six-factor solution with an eigenvalue 1.11 that explained $61.56 \%$ of the total variance of the scale. Additionally, one factor with an eigenvalue of 9.87 explained $32.91 \%$ of the total variance (Figure 1 ).

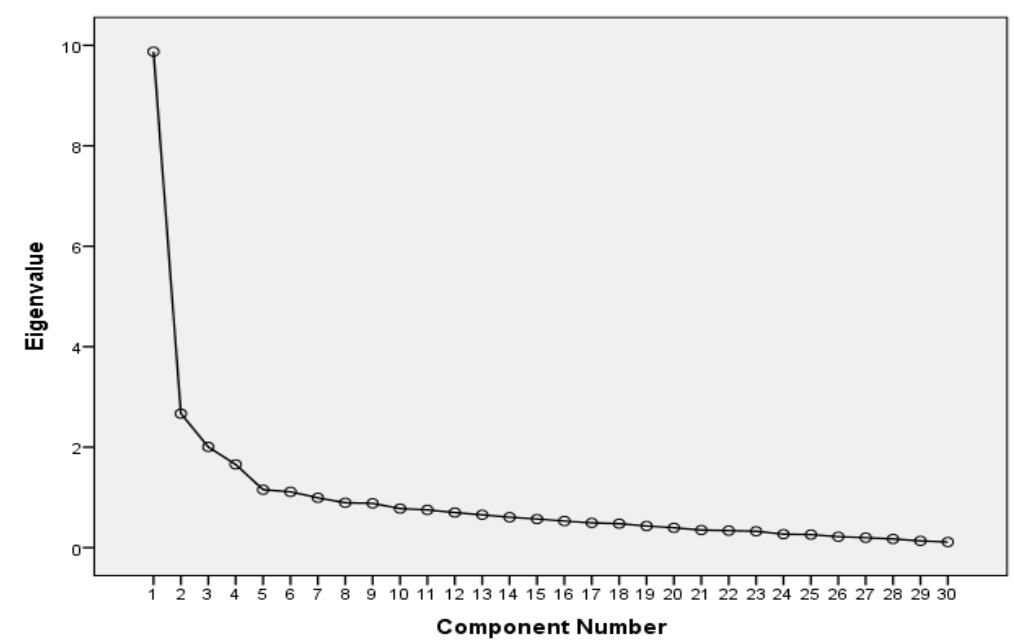

Figure 1. Scree Plot. 
In the original scale by Ku et al. (2010), a varimax rotation was performed concerning the factor analysis. In this study, a varimax rotation method with Kaiser normalization was also conducted, and the results indicated a six-factor solution (Table 5).

The six factor solution shows that the items were assigned as follows: factor one $(1,2,3,4,7,9,10$, $11,12,13,14$, and 25), factor $2(27,28,29$ and 30), factor $3(20,21,22$ and 26), factor 4 (5, 6, 19 and 23), factor $5(15,16,17$ and 18) and factor 6 (8 and 24).

Although the original scale had four domains, in this study, the factor analysis resulted in six components. A varimax rotation with four fixed number of factors was performed (Table 6). The four-factor solution with an eigenvalue of 1.65 explained $54.01 \%$ of the total variance of the scale; this value is in agreement with Tabachnick and Fidell (Tabachnick and Fidell [1983] 2013), who recommend variance values between $50.0-60.0 \%$.

The four factor solution (Table 6) demonstrates that the items were assigned as follows: factor one $(1,2,3,4,5,6,7,9,10,11,12,13,14$, and 15), factor $2(27,28,29$, and 30), factor $3(20,21,22$, and 26), and factor $4(8,16,17,18$, and 24$)$.

When comparing the two models, a 4-factor solution was a more valid solution. A 6-factor solution raised some questions, since domain 6 was a very poor measure, only comprising 2 items (item 8 and item 24).

Table 5. Varimax rotation method in the SDS.

\begin{tabular}{|c|c|c|c|c|c|c|}
\hline & \multicolumn{6}{|c|}{ Components } \\
\hline & 1 & 2 & 3 & 4 & 5 & 6 \\
\hline SDS 1 (shock) & 0.70 & 0.46 & 0.05 & 0.16 & 0.06 & 0.14 \\
\hline SDS 2 (denial) & 0.68 & 0.28 & -0.03 & 0.17 & 0.04 & 0.08 \\
\hline SDS 3 (fear) & 0.74 & 0.04 & -0.18 & 0.03 & 0.14 & -0.14 \\
\hline SDS 4 (suffering) & 0.71 & 0.26 & -0.13 & 0.02 & -0.04 & 0.30 \\
\hline SDS 5 (sorrow) & 0.38 & 0.37 & 0.11 & 0.44 & 0.08 & 0.02 \\
\hline SDS 6 (loneliness) & 0.39 & 0.20 & 0.08 & 0.72 & -0.02 & 0.04 \\
\hline SDS 7 (numb) & 0.678 & 0.39 & 0.10 & 0.28 & 0.03 & 0.18 \\
\hline SDS 8 (regret) & 0.33 & 0.19 & -0.05 & 0.32 & 0.31 & 0.42 \\
\hline SDS 9 (discontented) & 0.71 & 0.09 & 0.07 & 0.26 & 0.21 & -0.01 \\
\hline SDS 10 (worry) & 0.70 & -0.05 & -0.02 & 0.16 & 0.27 & -0.05 \\
\hline SDS 11 (fatalism) & 0.72 & 0.32 & 0.11 & 0.25 & -0.03 & 0.16 \\
\hline SDS 12 (giving up) & 0.54 & 0.38 & 0.19 & 0.29 & -0.08 & -0.05 \\
\hline SDS 13 (pessimistic) & 0.69 & 0.24 & 0.11 & 0.18 & -0.05 & -0.13 \\
\hline SDS 14 (my mind) & 0.57 & 0.19 & 0.27 & 0.20 & 0.18 & -0.01 \\
\hline SDS 15 (satisfied by others) & 0.25 & 0.20 & 0.28 & 0.33 & 0.43 & -0.21 \\
\hline SDS 16 (trust others) & 0.08 & -0.20 & 0.13 & 0.23 & 0.62 & -0.14 \\
\hline SDS 17 (obey others) & -0.02 & 0.17 & 0.01 & -0.06 & 0.72 & 0.23 \\
\hline SDS 18 (forgive others) & 0.27 & 0.18 & 0.11 & -0.03 & 0.67 & 0.27 \\
\hline SDS 19 (alienated) & 0.30 & 0.09 & 0.16 & 0.76 & 0.04 & 0.22 \\
\hline SDS 20 (respect for God) & 0.00 & -0.11 & 0.831 & 0.16 & 0.05 & -0.04 \\
\hline SDS 21 (God is powerless) & -0.01 & -0.08 & 0.75 & 0.12 & 0.13 & -0.04 \\
\hline SDS 22(my ancestors) & 0.18 & 0.03 & 0.63 & -0.09 & 0.06 & 0.29 \\
\hline SDS 23 (faith) & 0.22 & 0.16 & -0.14 & 0.47 & 0.22 & -0.21 \\
\hline SDS 24 (sinful) & -0.05 & 0.04 & 0.04 & 0.03 & 0.12 & 0.73 \\
\hline SDS 25 (peace of mind) & 0.59 & -0.03 & 0.25 & 0.21 & 0.33 & -0.20 \\
\hline SDS 26 (religious activities) & -0.01 & 0.26 & 0.73 & -0.06 & 0.00 & -0.05 \\
\hline SDS 27 (discuss death) & 0.34 & 0.73 & -0.03 & 0.04 & 0.25 & -0.06 \\
\hline SDS 28 (dying situation) & 0.39 & 0.63 & 0.02 & 0.13 & 0.08 & -0.03 \\
\hline SDS 29 (dying ceremony) & 0.15 & 0.83 & 0.06 & 0.13 & -0.14 & 0.05 \\
\hline SDS 30 (after death) & 0.15 & 0.83 & -0.01 & 0.15 & 0.07 & 0.16 \\
\hline
\end{tabular}


Table 6. Rotated component matrix with four components.

\begin{tabular}{|c|c|c|c|c|}
\hline & \multicolumn{4}{|c|}{ Components } \\
\hline & 1 & 2 & 3 & 4 \\
\hline SDS 1 (shock) & 0.67 & 0.50 & 0.02 & 0.11 \\
\hline SDS 2 (denial) & 0.65 & 0.32 & -0.05 & 0.06 \\
\hline SDS 3 (fear) & 0.70 & 0.02 & -0.21 & 0.03 \\
\hline SDS 4 (suffering) & 0.58 & 0.38 & -0.18 & 0.09 \\
\hline SDS 5 (sorrow) & 0.53 & 0.35 & 0.16 & 0.07 \\
\hline SDS 6 (loneliness) & 0.63 & 0.22 & 0.16 & -0.03 \\
\hline SDS 7 (numb) & 0.69 & 0.45 & 0.09 & 0.09 \\
\hline SDS 8 (regret) & 0.40 & 0.24 & -0.02 & 0.45 \\
\hline SDS 9 (discontented) & 0.76 & 0.09 & 0.06 & 0.14 \\
\hline SDS 10 (worry) & 0.72 & -0.06 & -0.04 & 0.17 \\
\hline SDS 11 (fatalism) & 0.71 & 0.40 & 0.08 & 0.03 \\
\hline SDS 12 (giving up) & 0.59 & 0.40 & 0.19 & -0.10 \\
\hline SDS 13 (pessimistic) & 0.70 & 0.25 & 0.08 & -0.12 \\
\hline SDS 14 (my mind) & 0.61 & 0.17 & 0.26 & 0.12 \\
\hline SDS 15 (satisfied by others) & 0.44 & 0.05 & 0.33 & 0.27 \\
\hline SDS 16 (trust others) & 0.26 & -0.35 & 0.18 & 0.45 \\
\hline SDS 17 (obey others) & 0.02 & 0.01 & 0.03 & 0.75 \\
\hline SDS 18 (forgive others) & 0.27 & 0.08 & 0.11 & 0.71 \\
\hline SDS 19 (alienated) & 0.55 & 0.15 & 0.25 & 00.09 \\
\hline SDS 20 (respect for God) & 0.07 & -0.12 & 0.84 & -0.01 \\
\hline SDS 21 (God is powerless) & 0.05 & -0.11 & 0.75 & 0.06 \\
\hline SDS 22(my ancestors) & 0.08 & 0.11 & 0.57 & 0.16 \\
\hline SDS 23 (faith) & 0.45 & 0.05 & -0.05 & 0.09 \\
\hline SDS 24 (sinful) & -0.13 & 0.20 & 0.03 & 0.43 \\
\hline SDS 25 (peace of mind) & 0.68 & -0.11 & 0.25 & 0.15 \\
\hline SDS 26 (religious activities) & -0.02 & 0.22 & 0.71 & -0.02 \\
\hline SDS 27 (discuss death) & 0.37 & 0.63 & -0.01 & 0.23 \\
\hline SDS 28 (dying situation) & 0.41 & 0.59 & 0.03 & 0.09 \\
\hline SDS 29 (dying ceremony) & 0.17 & 0.82 & 0.08 & -0.04 \\
\hline SDS 30 (after death) & 0.67 & 0.50 & 0.02 & 0.11 \\
\hline
\end{tabular}

\subsection{Reliability}

Reliability is related to the consistency of a measure (Heale and Twycross 2015). One of the measures of reliability is the internal consistency, which allows measuring if all the items on a scale measure one construct; the most commonly test used is Cronbach's alpha (Heale and Twycross 2015). The overall internal consistency of the European Portuguese version of the SDS revealed a good Cronbach's alpha value (0.91); also, all Cronbach's alpha values were above 0.90 if an item was deleted (Table 7).

The construct validity showed that significant correlations between the individual SDS items and the total score ranged from 0.14 to $0.79(p<0.01)$; the item with the highest correlation was item 7 "I feel numb", and the lowest was item 24, "I feel sinful" (Table 7).

The internal validity of all SDS domains is described in Table 8. 
Table 7. Item-total statistics and Cronbach's alpha if an item was deleted from the SDS.

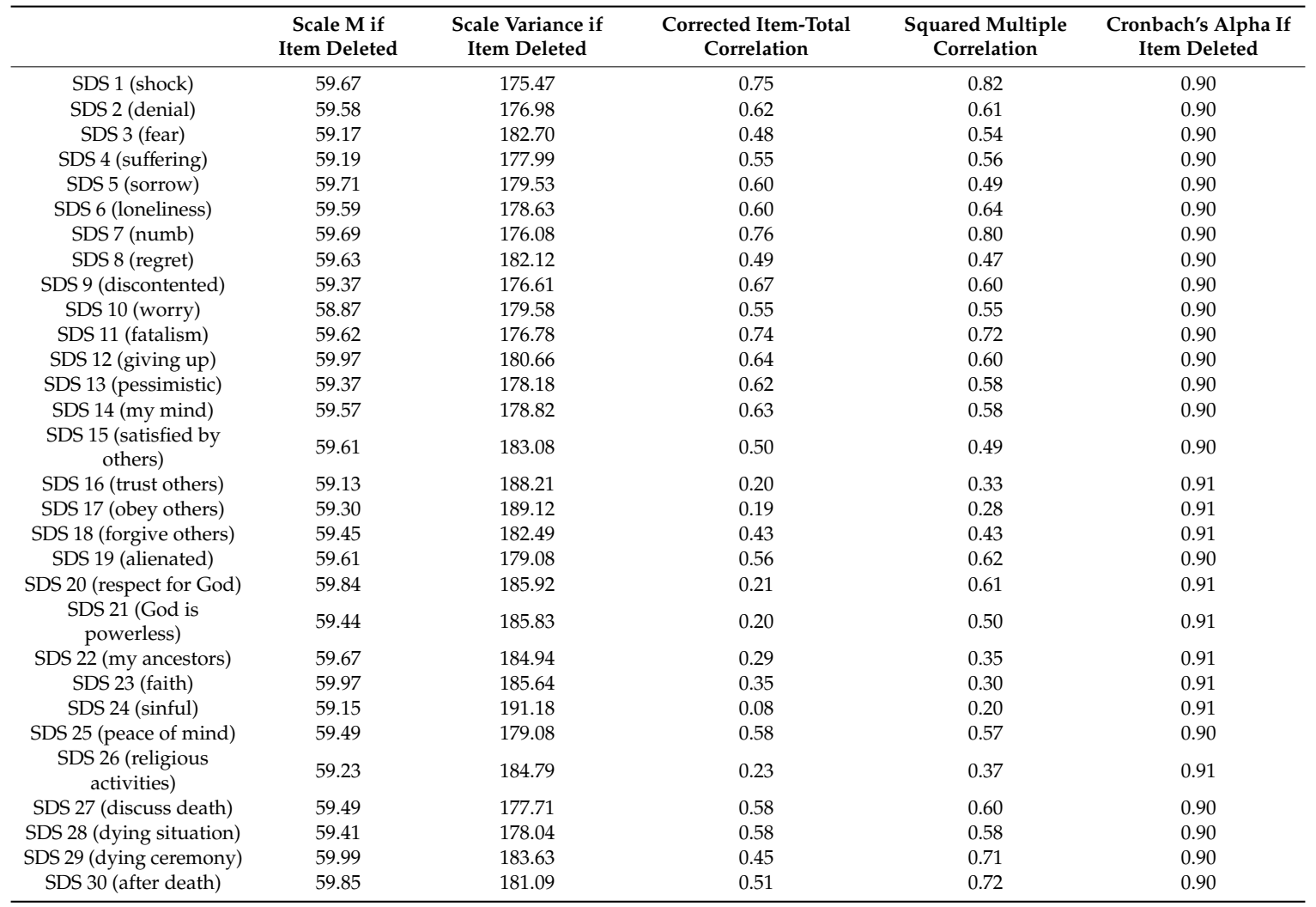

Table 8. Cronbach's alpha of the four domains of the SDS.

\begin{tabular}{cc}
\hline Domains & Cronbach's $\alpha$ \\
\hline Relationship with self & 0.92 \\
Relationship with others & 0.63 \\
Relationship with God & 0.64 \\
Facing death & 0.85 \\
\hline
\end{tabular}

Correlation between all the domains of the SDS was achieved, and the values ranged between 0.20 and 0.62 (Table 9).

Table 9. Correlation between all the domains of the SDS.

\begin{tabular}{lcccc}
\hline \multicolumn{1}{c}{ Domains } & $\begin{array}{c}\text { Facing Death } \\
\text { Domain }\end{array}$ & $\begin{array}{c}\text { Relationship with } \\
\text { Others Domain }\end{array}$ & $\begin{array}{c}\text { Relationship with } \\
\text { God Domain }\end{array}$ & $\begin{array}{c}\text { Relationship with } \\
\text { Self Domain }\end{array}$ \\
\hline Facing death domain & - & & & \\
Relationship with others domain & $0.30^{* *}$ & - & - & - \\
Relationship with God domain & $0.20^{*}$ & $0.43^{* *}$ & $0.33^{* *}$ & - \\
Relationship with self domain & $0.62^{* *}$ & $0.52^{* *}$ & & - \\
\hline
\end{tabular}

${ }^{* *}$ Correlation is significant at the 0.01 level (2-tailed). ${ }^{*}$ Correlation is significant at the 0.05 level (2-tailed).

\subsection{Divergent Validity}

The divergent construct validity is when the instrument measures the construct opposite to the constructs measured by a new instrument (Gray et al. [1987] 2017). In order to perform this type of validity, the Spiritual Well-Being Questionnaire (SWBQ) (Gouveia et al. 2009) was used, since according to the literature, there is negative correlation between SWB and spiritual distress (Caldeira et al. 2017). First, this procedure was necessary to transform the variables of the $\mathrm{Z}$ scores because the two scales 
had different Likert variable scores. Then, a correlation between the SDS and the SWBQ (Pearson coefficient $r=-0.26$; $p$-value $=0.001$ ) was performed, and the results suggested a statistically weak negative correlation. This correlation was observed with a trend line on the scatter plot (Figure 2).

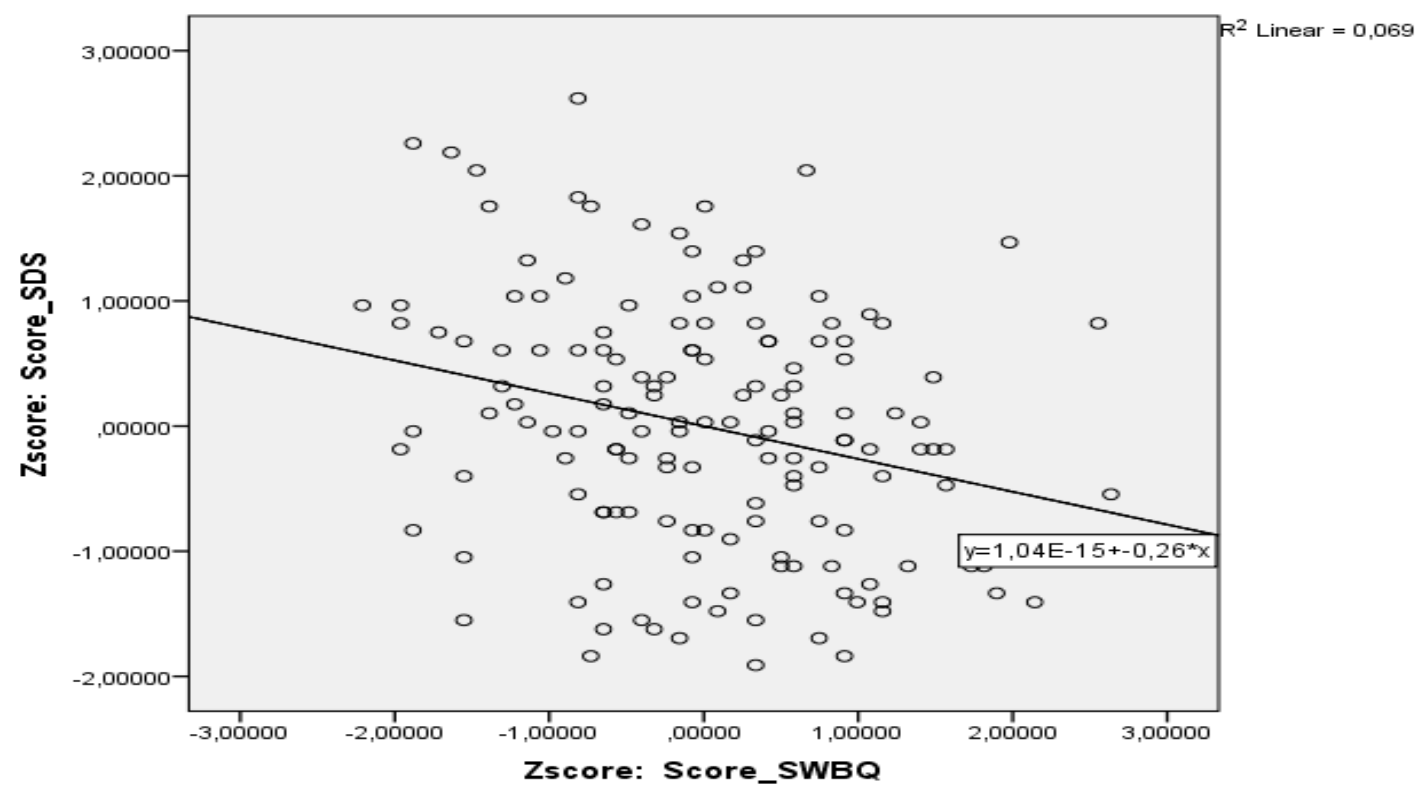

Figure 2. Scatter plot of the divergent validity between the SDS and the SWBQ.

A moderate correlation between the SDS and the personal domain of SWBQ was found (Table 10), as well as a statistically weak correlation between the communal and transcendental domain.

Table 10. Correlation between the four domains of the SWBQ and the SDS.

\begin{tabular}{|c|c|c|c|c|c|c|}
\hline Domains & $\begin{array}{l}\text { Personal } \\
\text { Domain }\end{array}$ & $\begin{array}{c}\text { Communal } \\
\text { Domain }\end{array}$ & $\begin{array}{l}\text { Environmenta } \\
\text { Domain }\end{array}$ & $\begin{array}{l}\text { Transcendental } \\
\text { Domain }\end{array}$ & $\begin{array}{c}\text { Score } \\
\text { SWBQ }\end{array}$ & Score SDS \\
\hline Personal domain & - & & & & & \\
\hline Communal domain & $0.67 * *$ & - & & & & \\
\hline Environmental domain & $0.24^{* *}$ & $0.39 * *$ & - & & & \\
\hline Transcendental domain & $0.20 *$ & $0.26^{* *}$ & $0.19 *$ & - & & \\
\hline Score SWBQ & $0.64^{* *}$ & $0.72 * *$ & $0.67^{* *}$ & $0.72 * *$ & - & \\
\hline Score SDS & $-0.52^{* *}$ & $-0.25^{* *}$ & 0.018 & -0.11 & $-0.26^{* *}$ & - \\
\hline
\end{tabular}

** Correlation is significant at the 0.01 level (2-tailed). ${ }^{*}$ Correlation is significant at the 0.05 level (2-tailed).

\section{Discussion}

Upon arriving at this phase, the initial predefined objectives were achieved. The SDS European Portuguese has been translated, adapted and validated with good psychometric characteristics. The methodology used (Sousa and Rojjanasrirat 2011) has the advantage of having being developed to be applied specifically in healthcare frameworks.

The SDS has the advantage of having a broader assessment when comprising the domain "relationship with others" (Ku et al. 2010). This allows measuring the interaction of cancer patients with significant others, which is an important domain of spirituality and particularly important to cancer patients in times of thinking identify and their own existence, as a unique individual, and also of value to others (Ku et al. 2010). The final version of the SDS European Portuguese kept the same 30 items of the original scale; however, in Simão et al. (2015) the final version had 28 items since item 22 and item 24 were deleted because the factorial loadings were below 0.3 .

Concerning the scores of the SDS in our study, the results shows that $49.3 \%$ had moderate spiritual distress, and $6.7 \%$ had severe spiritual distress. The prevalence of the nursing diagnosis spiritual 
distress was $40.8 \%$ in cancer patients receiving chemotherapy (Caldeira et al. 2017). Also, in a study conducted in palliative care by Velosa et al. (2017), the prevalence of spiritual distress was $23 \%$. More recently, Lestari et al. (2018) suggested that $32.2 \%$ of women with breast cancer had moderate spiritual distress and $5.4 \%$ had severe spiritual distress.

The overall Cronbach's alpha was 0.91 , which is considered a good value according to the literature (Gray et al. [1987] 2017). SDS has the ability to measure one construct, which is spiritual distress, and this is quite important for an accurate diagnosis and intervention. Comparing the reliability with the validation of the Brazilian Portuguese SDS, which was performed by Simão et al. (2015), the Cronbach's alpha was 0.87 , which means that the results of Cronbach's alpha in this study are slightly higher. Examining the internal reliability of the four domains of the SDS, in the domain "relationship with others" Cronbach's alpha was 0.63 , whereas in the domain "relationship with God", Cronbach's alpha was 0.64 . These values of the subscales are more acceptable than those reported by Simão et al. (2015). Regarding the "relationship with self" and "facing death" domains, the results also achieved a higher reliability compared with Simão et al. (2015).

The factorial analysis performed by varimax rotation allowed the identification of six component, which used the rule of Guttman-Kaiser. However, this rule was not followed; instead, a fixed 4-component rotation was carried out. The six-factor solution was not considered as a valid solution since domain 6 only comprised two items. Interestingly, some items migrated to different domains compared to the original version of the scale. The main reason relates to participants' interpretations of these items, which is particularly important to consider when assessing spirituality, which is a subjective and individual experience. Additionally, the cultural background may lead to these differences regarding the psychometric properties of the SDS. When comparing the results of the factor analysis with Simão et al. (2015), four factor components also emerged, and both results are in agreement with the original scale. Nonetheless, no information is available concerning the type of rotation used and if the Guttman-Kaiser rule was respected in the study of Simão et al. (2015).

The divergent construct validity of this scale was reached, although there is a statistically weak negative correlation. Comparing the divergent validation process with Simão et al. (2015), in which they also applied the SWBQ, they obtained a higher correlation value $(r=-0.46 ; p$-value $<0.001)$ compared with this study.

One of the difficulties of this study was the fact that there was only one validation of the SDS published. This limited the discussion since we could not compare our findings to the results of other studies.

Limitations of this study are the following: first, the use of the convenience sampling technique; second, a sample with homogeneity in a religious profile; and third, the test-retest assessment was not conducted but would improve the accurate reliability. The latter procedure was not performed primarily because cancer patients are a vulnerable population. Notwithstanding, the limitations of this study, this is the first scale validated regarding spiritual distress in Portugal that allowed accurate assessment of this nursing diagnosis in clinical practice.

Future research may consider testing this scale in other settings, contexts and religious profiles. Similarly, the domains of the SDS "relationship with others" and "relationship with God" could be improved in order to enhance internal reliability. As there are few available scales to assess the nursing diagnosis spiritual distress, another important suggestion for future research would be the development of other scales in order to have more available tools to conduct an accurate assessment of spiritual distress. 


\section{Conclusions}

Overall, results indicate that the SDS European Portuguese version has reasonable psychometric characteristics, as well as high construct validity with item loading in a four-factor model. Results showed both high reliability and high internal consistency.

The validation of the European Portuguese SDS scale in the context of cancer patients is an added value in nursing clinic practice because this tool may facilitate the clinical reasoning process in cancer patients with spiritual distress, in order to plan interventions that reestablish spiritual health and spiritual well-being in cancer patients.

Author Contributions: H.M. and S.C. conceived and designed the study, collected and analyzed the data and wrote the paper. T.D.D. analyzed the data and wrote the paper. M.V. wrote the paper. Y.-L.K. wrote the paper and gave expertise counseling.

Funding: This research received no external funding.

Conflicts of Interest: The authors declare no conflict of interest.

\section{References}

Bahraini, Sayna, Wendy Gifford, Ian D. Graham, Liquaa Wazni, Suzette Brémault-Phillips, Rebekah Hackbusch, Catrine Demers, and Mary Egan. 2019. The accuracy of measures in screening adults for spiritual suffering in health care settings: A systematic review. Palliative and Supportive Care 7: 1-14. [CrossRef]

Best, Megan, Lynley Aldridge, Phyllis Butow, Ian Oliver, Melanie Price, and Fleur Webster. 2015. Assessment of Spiritual Suffering in the Cancer Context: A Systematic Literature Review. Palliative and Supportive Care 13: 1335-61. [CrossRef]

Bornet, Marc-Antoine, Etienne Rochat, Anne-Véronique Dürst, Sarah Fustinoni, Christophe Büla, Armin von Gunten, and Stéfanie Monod. 2016. Instruments to Assess Depressive Symptoms and Spiritual Distress Investigate Different Dimensions. Clinical Gerontologist 39: 104-16. [CrossRef]

Büssing, Arndt, Andreas Günther, Klaus Baumann, Eckhard Frick, and Christoph Jacobs. 2013. Spiritual Dryness as a Measure of a Specific Spiritual Crisis in Catholic Priests: Associations with Symptoms of Burnout and Distress. Evidence-Based Complementary and Alternative Medicine 2013: 246797. [CrossRef]

Büssing, Arndt, Daniela Rodrigues Recchia, Koenig Harold, Klaus Baumann, and Eckhard Frick. 2018. Factor Structure of the Spiritual Needs Questionnaire (SpNQ) in Persons with Chronic Diseases, Elderly and Healthy Individuals. Religions 9: 13. [CrossRef]

Caldeira, Sílvia, Emília Campos Carvalho, and Margarida Vieira. 2013. Spiritual Distress-Proposing a New Definition and Defining Characteristics. International Journal of Nursing Knowledge 24: 77-84. [CrossRef]

Caldeira, Sílvia, Fiona Timmins, Emília Campos Carvalho, and Margarida Vieira. 2017. Spiritual Well-Being and Spiritual Distress in Cancer Patients Undergoing Chemotherapy: Utilizing the SWBQ as Component of Holistic Nursing Diagnosis. Journal of Religion \& Health 56: 1489-502. [CrossRef]

Caldeira, Sílvia, Joana Romeiro, and Helga Martins. 2019. The Role of the Nurse in Providing Spiritual Care: A Case Study Approach to Exploring Specific Care Provision by Healthcare Workers in the Context of an Interdisciplinary Healthcare Team. In Spirituality in Healthcare: Perspectives for Innovative Practice. Edited by Fiona Timmins and Sílvia Caldeira. Cham: Springer, pp. 117-42.

Draper, Peter. 2012. An Integrative Review of Spiritual Assessment: Implications for Nursing Management. Journal of Nursing Management 20: 970-98. [CrossRef]

Gomez, Rapson, and John W. Fisher. 2003. Domains of Spiritual Well-Being and Development and Validation of the Spiritual Well-Being Questionnaire. Personality and Individual Differences 35: 1975-91. [CrossRef] 
Gomez, Rapson, and John W. Fisher. 2005a. Item Response Theory Analysis of the Spiritual Well-Being Questionnaire. Personality and Individual Differences 38: 1107-21. [CrossRef]

Gomez, Rapson, and John W. Fisher. 2005b. The Spiritual Well -Being Questionnaire: Testing for Model Applicability, Measurement and Structural Equivalencies, and Latent Mean Differences Across Gender. Personality and Individual Differences 39: 1383-93. [CrossRef]

Gouveia, Maria João, Marta Marques, and José Luís Pais-Ribeiro. 2009. Versão Portuguesa do Questionário de Bem-Estar Espiritual (SWBQ): Análise Confirmatória da sua Estrutura Factorial. Psicologia, Saúde E Doenças 10: 285-93.

Gray, Jennifer R., Susan K. Grove, and Suzanne Sutherland. 2017. Burns and Grove's the Practice of Nursing Research: Appraisal, Synthesis, and Generation of Evidence, 8th ed. Grand Rapids: Elsevier, 738p. First published 1987.

Guttman, Louis. 1954. Some Necessary Conditions for Common Factor Analysis. Psychometrika 19: 149-61. [CrossRef]

Heale, Roberta, and Alison Twycross. 2015. Validity and Reliability in Quantitative Research. Evidence-Based Nursing 18: 66-67. [CrossRef]

Herdman, Heather T., and Shigemi Kamitsuru, eds. 2018. NANDA: NANDA International Nursing Diagnoses: Definitions and Classification 2018-2020, 11th ed. Chichester and Ames: Wiley-Blackwell, 1187p. First published 1994.

Kaiser, Henry F. 1961. A Note on Guttman's Lower Bound for the Number of Common Factors. British Journal of Psychology 14: 1-2. [CrossRef]

Kopacz, Marek S., Claire A. Hoffmire, Sybil W. Morley, and C. Garland Vance. 2015. Using a Spiritual Distress Scale to Assess Suicide Risk in Veterans: An Exploratory Study. Pastoral Psychology 64: 381-90. [CrossRef]

Ku, Ya-Lie. 2005. Spiritual Distress Experienced by Cancer Patients-Develop a Spiritual Care for Cancer Patients. Taiwan Journal of Hospice Palliative Care 10: 221-33.

$\mathrm{Ku}$, Ya-Lie, Shih-Ming Kuo, and Ching-Yi Yao. 2010. Establishing the Validity of a Spiritual Distress Scale for Cancer Patients Hospitalized in Southern Taiwan. International Journal of Palliative Nursing 16: 133-37. [CrossRef]

Lestari, Puji, Aan Nuraeni, and Dyah Setyorini. 2018. Spiritual Distress in Breast Cancer Patients. Journal of Nursing Care 1: 155-63. [CrossRef]

Martins, Helga, and Sílvia Caldeira. 2018. Spiritual Distress in Cancer Patients: A Synthesis of Qualitative Studies. Religions 9: 285. [CrossRef]

Martins, Ana Raquel, Sara Pinto, Sílvia Caldeira, and Francisco Luís Pimentel. 2015. Translation and Adaptation of the Spirituality and Spiritual Care Rating Scale in Portuguese Palliative Care Nurses. Revista de Enfermagem Referência 4: 89-97. [CrossRef]

Monod, Stéfanie, Mark Brennan, Etienne Rochat, Estelle Martin, Stéphane Rochat, and Christophe J. Büla. 2011. Instruments Measuring Spirituality in Clinical Research: A Systematic Review. Journal of General Internal Medicine 26: 1345-57. [CrossRef]

Munro, Barbara Hazard. 2005. Statistical Methods for Health Care Research, 5th ed. Philadelphia: Lippincott Williams \& Wilkins, 577p. First published 1986.

Seddigh, Ruohollah, Amir-Abbas Keshavarz-Akhlaghi, and Somayeh Azarnik. 2016. Questionnaires Measuring Patients' Spiritual Needs: A Narrative Literature Review. Iranian Journal of Psychiatry and Behavioral Sciences 10: e4011. [CrossRef]

Simão, Talita Pardo, Erika de Cassia Lopes Chaves, Emília Campos de Carvalho, Denismar Alves Nogueira, Camila Csizmar Carvalho, Ya-Lie Ku, and Denise Hollanda Iunes. 2015. Cultural Adaptation and Analysis of the Psychometric Properties of the Brazilian Version of the Spiritual Distress Scale. Journal of Clinical Nursing 25: 231-39. [CrossRef]

Sousa, Valmi D., and Wilaiporn Rojjanasrirat. 2011. Translation, Adaptation and Validation of Instruments or Scales for use in Cross-Cultural Health Care Research: A Clear and User-Friendly Guideline. Journal of Evaluation in Clinical Practice 17: 268-74. [CrossRef]

Tabachnick, Barbara G., and Linda S. Fidell. 2013. Using Multivariate Statistics, 6th ed. Harlow: Pearson Education Limited Harlow, 1061p. First published 1983.

Taylor, Elizabeth, and Iris Mamier. 2013. Nurse Responses to Patient Expressions of Spiritual Distress. Holistic Nursing Practice 27: 217-24. [CrossRef] 
Velosa, Teresa, Sílvia Caldeira, and Manuel Luís Capelas. 2017. Depression and Spiritual Distress in Adult Palliative Patients: A Cross-Sectional Study. Religions 8: 156. [CrossRef]

Waltz, Carolyn, Ora Lea Strickland, and Elizabeth Lenz. 2016. Measurement in Nursing and Health Research, 5th ed. New York: Springer, 632p. First published 1991. 